\title{
O ensino de história e o PIBID História UFC: práticas docentes a partir da história pública ${ }^{1}$
}

\author{
History teaching and PIBID UFC-History: teaching practices from \\ Public History
}

\section{L'enseignement de l'histoire et le PIBID Histoire UFC: pratiques professorales à partir de l'histoire publique}

\author{
Ana Carla Sabino Fernandes 2 \\ Universidade Federal do Ceará, Departamento de História, Professora adjunto II. \\ https://orcid.org/0000-0001-9942-1881
}

Resumo: Este artigo compartilha algumas atividades docentes pautadas em apropriações conceituais e bibliográficas acerca da História Pública para o ensino e a aprendizagem histórica. As atividades, no formato teórico-metodológico de aula-oficina e em sequências didáticas, foram realizadas pelo Programa Institucional de Bolsa de Iniciação à Docência (P|BID)/Subprojeto História da Universidade Federal do Ceará (UFC) e desenvolvidas em três escolas públicas do Estado do Ceará, entre os anos de 2015-2017 e no primeiro bimestre de 2018, período em que coordenei o referido programa. Consideramos, em nossas práticas docentes, as narrativas estudantis sobre a ideia histórica de "público" como fundamentais para a construção dos saberes históricos dos alunos na escola e obtivemos como resultado o fomento da docência significativa dos futuros professores.

Palavras-chave: Ensino de História. PIBID História UFC. História pública. Formação inicial docente. Saber histórico escolar.

Abstract: This paper shares some teaching activities based on conceptual and bibliographical appropriations about the importance of Public History for teaching and learning of History. The activities were shown as a theoretical-methodological workshop class, as well as didactic sequences. These

Programa Institucional de Bolsa de Iniciação à Docência (PIBID)/Subprojeto História da UFC. Este artigo tratará de experiências docentes construídas e vividas, pelo PIBID História UFC, nas escolas, no Laboratório de Ensino e Aprendizagem Histórica (LEAH) e no Grupo de Estudo e Pesquisa em Ensino de História (GEPEH), ambos (LEAH e GEPEH) situados no Dept ${ }^{\circ}$ de História da UFC, nos anos de 2015-2017 e no primeiro bimestre de 2018. Agradeço a colaboração da aluna bolsista PIBID História Maria do Céu Colares Botelho Neta, bolsista entre fevereiro de 2017 e fevereiro de 2018 (atualmente professora de história da educação básica), por compartilhar comigo seus relatos sobre história pública e aprendizado docente a partir das ações pibidianas. Dedico este artigo a todos os alunos e professores bolsistas do PIBID História UFC e aos estudantes das escolas que acreditaram em nossa capacidade de ensinar História para a vida. 0 programa PIBID História UFC continua existindo e resistindo e, desde meados de 2018, tornou-se PIBID História e Sociologia UFC.

2 Doutora em História Universidade do Vale do Rio dos Sinos; Mestre em História pela Universidade Federal do Ceará. 
activities were carried out by the Institutional Program for Teaching Initiation Scholarship - PIBID lin Portuguese abbreviation//History Subproject of the Federal University of Ceará, UFC. I applied these experience in three Public Schools of the State of Ceará all years-long of 2015 and 2017 and during the first two months of 2018 , in which time I coordinated the program. I consider, in our teaching practices, the student narratives about the historical idea of "public" as a fundamental concept for the construction of the students' historical knowledge in the school. As a result, I obtained, the promotion of the significant-teaching of the undergraduate students of History.

Keywords: History teaching. PIBID UFC History. Public History. Teacher training. History of educational knowledge.

Résumé: Cet article partage quelques activités professorales basées sur des appropriations conceptuelles et bibliographiques autour de l'Histoire Publique pour l'enseignement et l'apprentissage historique. Les activités, en format théorique- métodologique de cours atelier et en séquences didactiques, ont été réalizées par le Programme Institutionnel de Bourses d'Iniciation à l'Enseignement - PIBID/Subprojet Histoire de I'Université Fédérale du Ceará - UFC, et développées dans trois écoles publiques de l'État du Ceará, dans les années 2015- 2017 et durant le premier bimestre de 2018, période pendant laquelle j'ai coordonné le dit programme. Nous considerons, dans nos pratiques professorales, les narrations étudiantes sur l'idée historique de "Public", comme fondamentales pour la construction de savoirs historiques des élèves de l'école et nous avons obtenu comme résultat le développement significatif des futurs professeurs.

Mots-Clés: Enseignement d'histoire. PIBID Histoire UFC. Histoire publique. Formation initiale professorale. Savoir historique scolaire.

Recebido em 6 de setembro de 2019 Aceito em 28 de fevereiro 2020

Publicado em 29 de julho de 2020

\section{1 Ô DE CASA, Ô DE FORA! O PIBID HISTÓRIA UFC E A DIFUSÃO DAS IDEIAS SOBRE PÚBLICO}

Este artigo apresenta experimentos, concretizados pelo PIBID História UFC lentre os anos de 2015-2017 e primeiro bimestre de 2018), fundamentais para a formação dos professores de história, tendo como fonte e objeto os estudos acerca da história pública, o pensamento e a relação dos jovens estudantes da escola com/sobre a ideia de público.

Considerando, portanto, a relação entre história pública e ensino, os usos da história pública em sala de aula pelos professores de história das escolas, a necessidade de 
pensarmos teoricamente sobre esses usos, tornando evidente o envolvimento dos saberes dos estudantes no processo de ensino e aprendizagem histórica, como enfatiza Ferreira (2018, p. 29-38) no artigo Qual a relação entre a história pública e o ensino de história?.

0 acompanhamento das aulas de história dos professores supervisores do PIBID e a observação de caráter etnográfico do ambiente escolar nos estimularam a desenvolver, primeiramente, pesquisas históricas com fontes documentais para saber operar com a ideia de público e para nos reconhecermos como público da história pelo viés da história pública. Isso porque precisávamos nos apropriar das dimensões da história pública não como mero suporte para dar sentido prático, plausível, público aos conteúdos históricos, mas como referência para a percepção da (re)significação dos saberes históricos pela sociedade em geral.

Nesse sentido, realizamos em 2017, no Arquivo Público do Estado do Ceará, a pesquisa enunciada como: "Ô de casa, $\hat{O}$ de foral, o Fundo Ministérios do Império do Brasil, fontes documentais para a nossa História, a História do Brasil/séc. XIX, documentos de arquivo e aprendizagem histórica no ensino médio." Os pibidianos pesquisadores comentaram o assunto principal do aviso ou ofício estudado, indicando quem são os interlocutores da correspondência oficial em questão, a partir dos saberes históricos/historiográficos adquiridos nas disciplinas de Teoria da História, História do Ceará e História do Brasil do currículo escolar de história (programas de ensino e literatura didática) das escolas participantes do PIBID, considerando a relevância e os usos públicos que a nossa sociedade atual atribui aos fatos e acontecimentos suscitados nos documentos em análise, como a questão da seca no Ceará.

Como resultado do cruzamento entre os conteúdos das fontes, a história ensinada e o compromisso com a divulgação, a difusão e a circulação do conhecimento histórico (princípios básicos da história pública), os pibidianos produziram sequências didáticas problematizando o poder público, a Presidência da Província do Ceará e o trato com o público, com setores marginalizados da sociedade cearense no século XIX. Como exemplo, cito o título de três sequências didáticas: $A$ seca como vetor da migração cearense entre 1888 e 1889, A seca em perspectiva historiográfica: o ontem e o hoje dos seus usos políticos e $A$ preocupação sanitária nos portos brasileiros na década de 1880, de autoria dos bolsistas Maria do Céu Botelho, Ana Mylena Costa e Luana Araújo da Silva; Élyssan Frota dos Santos e Lucas Fábio Parente; e Humberto Magalhães e Italo Alves, respectivamente.

Essas operações teóricas e metodológicas foram, portanto, basilares para - diálogo entre os saberes historiográficos, científicos, histórico-escolares, docentes, profissionais, discentes, escolares, socioculturais e pedagógicos e, consequentemente, propuseram elementos cruciais para a fabricação/realização da transposição didática do saber histórico, visando à formação da consciência histórica e crítica e à difusão das ideias sobre público e públicos da história por parte dos estudantes em processo de escolarização, 
professores das escolas, alunos em formação docente e professores dos cursos de licenciaturas em história.

\title{
2 NÓS E A HISTÓRIA PÚBLICA
}

\begin{abstract}
0 ensino no viés da história pública é um trabalho ampliado e de contínua mediação. A esperança é que os profissionais e estudantes não sejam seduzidos pelo "ouro de tolo" mercadológico, que imbui a ideia de produto com impacto de marketing. Do contrário, a educação aproxima-se perigosamente de uma dimensão de mercado. $E$ educação não pode ser entendida como mercadoria. 0 processo de ensino da disciplina e/ou da educação nãoescolar em História permanece assentado nos conteúdos, conceitos e fontes mobilizados para a elaboração de narrativas e significados históricos que favoreçam a reflexão do individuo em seu processo social. Os caminhos são seguidos por escolhas. Os rumos da história pública/ensino no Brasil são possibilidades, mas alguns criam a expectativa de horizontes promissores. A reflexão sobre essa relação qualifica a prática e a metodologia. Estimula a pensar o fazer e o refazer, uma reflexão-ação e vice-versa. 0 caminho se faz ao caminhar. (FERREIRA, 2018, p. 38, grifo do autor).
\end{abstract}

Em 2014 participei do $2^{\circ}$ Simpósio Internacional de História Pública na Universidade Federal Fluminense (UFF) e apresentei trabalho sobre a relação estabelecida entre centenas de pessoas e o Arquivo Público do Estado do Ceará, criado em 1932 por meio da doação de documentos diversos. Os doadores almejavam para si, com essas ações, a condição de sujeitos cientes da condição pública do documento de arquivo e viam no Arquivo Público o repositório ideal, além de ser o lugar/testemunho público desse ato. ${ }^{3}$

A partir desse estudo e com a orientação e a participação nas intervenções dos pibidianos nas escolas, pensei o quão amplas são as dimensões sociais acerca dos usos públicos da ideia de público quando tal conceito é ensinado pelo professor de história e pelos estudantes de história em formação docente (caso do PIBID História UFC) e discutido/posto em questão pelos estudantes das escolas.

Entendendo que as propostas e finalidades do PIBID e do PIBID História UFC são pautadas em situações-problemas e possibilidades de investigações empíricas acerca da aprendizagem histórica, passamos a focar na construção de saberes docentes para tratar das variadas noções de público e de história pública nas aulas de história. Partimos do nosso

0 trabalho intitulado "Dize-me como classificas e te direi quem és": as relações entre a procedência e o arquivamento de documentos doados ao Arquivo Público do Estado do Ceará em 1932 foi apresentado no Grupo de Trabalho História Pública e Patrimônio. 0 resumo do trabalho e mais detalhes sobre o evento constam em Vale (2014). 
compromisso enquanto agentes públicos transformadores, ou desejosos da transformação afetiva e efetiva da realidade social dos jovens estudantes.

Nossa vontade coletiva diante de uma problemática histórica, a dos usos públicos do público e da história pública, impulsionou a necessidade de "saber para, com ou por alguém" em vez de só "saber sobre alguém". Ou seja, essa problemática se transformou em plano de aula e de ensino, e compreendemos teoricamente a prática da práxis do professor de história que assume para si, para a universidade, para a comunidade e para a escola os diversos sujeitos e espaços partícipes dessa prática.

Assim, em junho de 2016, diante de um contexto histórico que clamava pela força e razão do ser público em nosso País, o Grupo de Estudo e Pesquisa em Ensino de História (GEPEH) do Dept ${ }^{\circ}$ de História da UFC, juntamente com o PIBID História UFC e outros participantes, propôs e promoveu a aula-oficina ${ }^{4}$ Os usos públicos e políticos da história em prol da democracia no Brasil: a literatura didática em questão.

Apostamos como pertinente e de interesse público a análise comparativa entre as diversas narrativas midiáticas acerca do conceito histórico de Democracia, no ano de 2016 - em decorrência do processo de Impeachment sofrido pela então Presidenta do Brasil Dilma Rousseff, aflorado nas redes sociais e no jornalismo/periodismo em muitos formatos e suportes -, e as narrativas historiográficas sobre o tema. Tendo o jovem estudante da escola como sujeito intercessor desses textos e as possíveis razões que o levariam ou não a ser influenciado e pelo que, por quem, para que seria influenciado.

Pensa-se, aqui, que influenciar, nesse cenário, é um verbo controverso, demasiado otimista e que se propaga e acontece mais pela competência dos poderes públicos (executivo, judiciário e legislativo), dos compartilhamentos das redes sociais e das transmissões das grandes emissoras de TV e rádio, do que pelo que o jovem estudante aprendeu ou poderá aprender com os professores pesquisadores nas aulas, nos documentos históricos e nos livros de história. Cito, portanto, Albiere (2011, p. 20):

\footnotetext{
[...] Podemos constatar a preocupação dos educadores não apenas com os modos de despertar interesse dos jovens por história, mas também com o tipo de história que deve ser apresentado na vida escolar. Uma parte dessa preocupação é transferida para a produção do livro didático. Essa é uma forma de publicação histórica extremamente importante e influente, já que o estabelecimento de um conteúdo curricular e sua expressão no texto didático acabam por balizar a educação histórica básica mais disseminada numa cultura.
}

\footnotetext{
4 Segundo Barca (apud OLIVEIRA, 2018, p. 79), no modelo da aula-oficina "L... o aluno é efetivamente visto como um dos agentes do seu próprio conhecimento, as atividades das aulas, diversificadas e intelectualmente desafiadoras, são realizadas por estes e os produtos daí resultantes são integrados na avaliação."
} 
Elaboramos, então, os seguintes argumentos (perguntas) para a concepção propositiva da aula-oficina: a disciplina história, a condição de professor, de aluno e a escola, existindo e acontecendo antes do rádio, da televisão e da internet, não seriam influenciadoras de saberes sábios, críticos, científicos sobre a democracia e a história para $\circ$ público, para a sociedade? Como responder e explicar, na perspectiva da didática da história, esse questionamento em sala de aula?

Selecionamos, para a primeira parte da aula-oficina, uma série de livros com conteúdos que explicam a Democracia no Brasil. Obras de Educação Moral e Cívica (EMC), de Organização Social e Política Brasileira (OSPB), manuais, compêndios e livros didáticos datados a partir da primeira metade do século XX até o ano de 2016. Precisávamos definir nosso recorte temporal preliminar pelo qual fosse possivel identificarmos a construção didática variada do conceito histórico de democracia no Brasil republicano. Também buscamos informações em sites hospedados no Google sobre "ensino de história e democracia", "história da democracia no Brasil" e "democracia do Brasil".

Destacamos, assim, registros apontados como marcos factuais e temporais que explicitam determinados usos públicos contemporâneos do termo/conceito de democracia no Brasil.

A culminância da aula-oficina ocorreu com a elaboração e a confecção coletiva da "Cronologia Histórica sobre a democracia no Brasil e a literatura didática de história, entre 1889-2016", a partir das fontes estudadas, objetivando o potencial epistemológico da Cronologia na/para a história escolar e o aprimoramento da percepção historicamente situada do conceito substantivo de democracia, exposto a estudantes e professores de história por meio, principalmente, dos livros didáticos. ${ }^{5}$

Na sequência, ou melhor, em 2017, com o acesso e o aprofundamento das leituras sobre história pública ${ }^{6}$ e a pungência do entendimento sobre os cruzamentos entre o público e a história, pelo aluno bolsista PIBID em iniciação docente em história, norteamos outro enorme desafio: o de explorar, nas aulas de história, a definição de público para além e aquém da coisa pública ligada às instituições de governo e do modelo de história política pautada, sobremaneira, nos ditos e feitos dos políticos e no (des)cumprimento das leis.

5 Vale ressaltar que, em jutho de 2018, o XVI Encontro Estadual de História do Ceará, realizado pela Associação Nacional de História (ANPUH) Ceará, teve como tema central do evento e dos debates, oportunamente, a questão da "História Pública e Democracia" (ENCONTRO ESTADUAL DE HISTÓRIA DO CEARÁ, 2018).

6 Consultar referências bibliográficas sobre História Pública no site da Rede Brasileira de História Pública: http://historiapublica. com.br/. 
Em nosso projeto de ensino e aprendizagem, por oportuno, estava escrito basicamente que a história ensinada, especialmente nas escolas, deveria também ensinar, por meio de currículos significativos, a seguinte verdade histórica: o público somos nós e o que fazemos, falamos e estamos por toda parte e em todos os tempos, no "palco" ou na "plateia" (CHARTIER, 2002). Afinal, o "palco" sem a "plateia" ou a "plateia" sem o "palco" é quase o mesmo que uma biblioteca sem leitores, uma escola distante da sociedade ou um arquivo público sem pesquisadores, ou melhor, são lugares não ocupados.

Essa metáfora exemplifica, desse modo, a necessidade real por parte dos docentes historiadores em reconhecer e trabalhar a palavra ou a fala curiosa, os insights dos discentes nas aulas de história (as interpretações, perguntas ou comentários, tantas vezes denominados de "senso comum" ou banalizados), como verbo pensado, representado e dito publicamente, no pleno exercício da liberdade de expressão, ato tão encorajado pelos historiadores nas narrativas historiográficas dos livros didáticos.

A vontade de ouvir foi uma boa lição reconhecida e aprendida pelo PIBID História em suas intervenções nas escolas, entre os anos de 2015-2018, com a total participação e parceria dos professores supervisores de três escolas públicas de ensino médio do Estado do Ceará, ${ }^{7}$ que cotidianamente incitam seus estudantes a querer falar e a conhecer. Ainda que o façam "perguntando a pergunta", sem saber ao certo como se colocar frente a tantas histórias: aquela contada pelo professor, a que está escrita nos livros ou a encenada nos filmes.

Os textos e a prática docente sobre e a partir da história pública nos falaram heuristicamente sobre audiência pública, autoria compartilhada, usos públicos do passado. $E$ daí, nós compreendemos mais sobre como acontece um diálogo sábio em sala de aula, capaz de ecoar no intuito de "quebrar os muros" que separam a história científica e a história escrita para um público não acadêmico, como dizem Almeida e Rovai (2011, p. 21):

Talvez a principal diferença entre o que a história pública propõe e o que a academia produz seja a ampliação do espaço e do seu público, e aos usos do conhecimento. Como poderemos ver, o trabalho fora da Universidade pode se expandir por meios dos arquivos, dos museus, da fotografia, do cinema, da história oral, sem, no entanto, perder em seriedade e compromisso com a produção de saberes.

Escola Cesar Cals (Prof. Ms. Pedro Trigueiro); Escola Liceu de Messejana (Prof. Ms. Jorge Sampaio) e Escola Liceu do Ceará (Profa. Regina Bernardo). Todas as escolas compõem a rede pública estadual de ensino do Ceará (ensino médio), localizadas na capital, Fortaleza. 
0 conceito de história pública, no contexto escolar, pode ser entendido como a história contada, ouvida, vivida, lembrada, ensinada e aprendida fora da academia e que atinge um número abrangente de pessoas, um público comum, que muitas vezes é privado de bens culturais, caso de boa parte da juventude que cursa o ensino médio. Visitações escolares a museus e sítios históricos que, por exemplo, "visam colocar o público em contato com um passado que, em geral, é apresentado como herança comum a todos" (ALBIERI, 2011, p. 21) são quase inexistentes.

A história deixa de ser restrita aos intelectuais conservadores que acreditam reter o conhecimento histórico, sujeitos "engolidos" pelos documentos dos arquivos e que só se exibem àqueles que acreditam ser merecedores.

Os professores de história parceiros do nosso grupo PIBID, aula após aula, reconheciam que sua função pública, social e de ofício dependia do diálogo profícuo com jovens alunos que buscam, muitas vezes, entender primeiro a si próprio para só assim conhecer o seu lugar no espaço público e no mundo.

As conversações foram suscitadas, em fins do ano de 2017, por meio de múltiplos exercícios que fundamentavam metodologicamente a relevância da espontaneidade da narrativa histórica do aluno na aula de história.

Um desses exercícios foi a atividade de pesquisa, construída a partir e com os estudantes do ensino médio, para entender um pouco mais sobre as aprendizagens do tempo pela juventude na perspectiva do ensino e da aprendizagem da história. Usamos como embasamento didático e teórico o texto de Araújo (2012, p. 66-77) A aula como desafio à experiência da história, interligando o modo como o autor explica o tempo presente, pensado como "presença" e "época" e a "aula", e o rótulo de que os "jovens são o futuro da nação", máxima proferida por educadores, entidades públicas (citamos somente esses grupos para sermos sucintos) e reverberada também por adolescentes estudantes das escolas públicas.

Para tanto, apresentamos aos alunos das escolas, como documentos geradores (FREIRE, 1975), imagens de três situações vividas ou vivenciadas pelos jovens, uma delas a propaganda do curso "Academia ENEM" de 2017 (PREFEITURA DE FORTALEZA, 2017) da Prefeitura Municipal de Fortaleza: ${ }^{8}$ 
Figura 1 - Propaganda do curso "Academia Enem" da Prefeitura de Fortaleza, CE, 2017

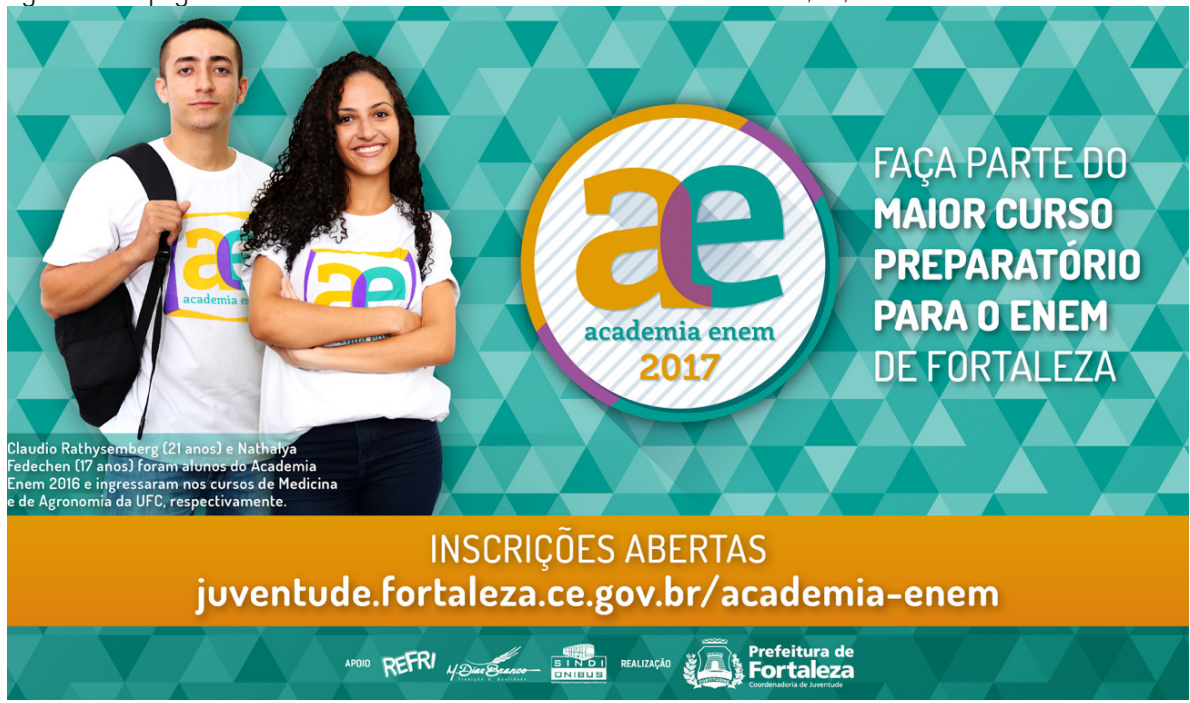

Fonte: Prefeitura de Fortaleza (2017).

Após a leitura do cartaz propaganda, o público-alvo retratado no anúncio, o jovem secundarista, deveria responder a duas perguntas: por que você lestudante do ensino médio) e nós somos partes desse tipo de registro histórico? 0 que vocês, nós e a história "temos a ver" com tudo isso?

Boa parte dos estudantes disse que a Prefeitura de Fortaleza cumpria sua obrigação público-governamental ao oferecer um cursinho "pré-enem" gratuito para que eles pudessem ter mais chances de concorrer com os estudantes das escolas particulares. $E$ que, assim, prevendo o ingresso na universidade pública, seriam cidadãos e responsáveis por transformar a história e melhorar a sociedade.

Em geral, os jovens aproveitaram o documento, as indagações e a folha pautada para revelar o quanto são "sonhadores do futuro" ao desejarem ter a aparência, o "jeito" de pessoas descoladas, inteligentes e serem capazes de ingressar nos Cursos de Medicina e de Agronomia da UFC como o garoto e a garota da propaganda.

Os relatos juvenis tornaram-se problematizações para a interpretação, a análise, o estudo e a experimentação praxiológica das relações entre tempo (temporalidades) e espaços (lugares) escolares no processo de "reinvenção" da escola e para o reconhecimento dos sujeitos estudantes como parte fundamental desse processo. Para tanto, consideramos imprescindíveis a desnaturalização, o estranhamento e a sensibilização como princípios curriculares norteadores da área de Ciências Humanas, para o reconhecimento da complexidade identitária dos sujeitos na/da escola, da cientificidade das Ciências Humanas 
na prática educativa e das "novas" tecnologias como aceleradores do tempo e marcos da mudança e do progresso para/entre os jovens estudantes.

Aprendemos, por fim, por meio do registro narrativístico, como o jovem aluno se percebe e percebe a sociedade em que vive, no tempo presente, e sua visão de público e de futuro circunscrito não só para ele, mas por ele.

\section{POR UMA HISTÓRIA PARA TODOS}

Indagações do tipo: "o que a história produz? Por que a história ensinada na escola é bem mais simples que a história ensinada da universidade? Quando acontecerá a $3^{a}$ guerra mundial?" e tantas outras inquietações colocadas pelos estudantes durante nossas aulasoficinas nos levaram a conclusão de que, cientes ou não, todos nós somos historiadores públicos, em virtude da necessidade de entender e divulgar o passado pelas lentes da história, da ciência da história e da didática da história, por conta da forma instantânea, intuitiva e instrumental como é questionada.

Estamos, dessa maneira, atribuindo mais um objetivo à lide do professor: a de corroborar com a formação da consciência histórica dos seus alunos e de todos que os circundam. Como tão bem sugere Wanderley (2018, p. 106-107) em Didática da história escolar. Um debate sobre o caráter público da história ensinada:

\footnotetext{
Por tudo o que apresentamos nesse texto, propomos uma didática da história escolar que, compreendendo-se parte de uma disciplina mais ampla que englobe os usos públicos da história e a própria ciência histórica, desloque-se da metodologia do ensino para uma área multidisciplinar articulada pela teoria da história, por saberes pedagógicos e outros de base sócio-antropológica (Cerri, 2010, p. 277). Que, rompendo com perspectivas tecnicistas, funcionalistas ou de sendo comum, seja capaz de construir um letramento histórico do mundo com uma orientação temporal perceptiva das múltiplas identificações em escola local e global.
}

E quem nunca ouviu a frase: "Mas pra que estudar história? História é muito chato, só fala de coisas do passado". De fato, estudar e aprender história requer tempo e dedicação, e a maioria dos jovens vê a vida muito instantaneamente, principalmente em virtude da internet e das redes sociais.

Essas questões são abrangentes e envolvem diferentes públicos, distintos por faixa etária ou por classe social, por expectadores assistindo ou comentando o filme ou 
a novela na TV, ou por adolescentes que dormem na sala de aula, por vezes na aula de História. São polifonias textuais da história pública, algo como história coletiva e colaborativa, sendo bastante difícil delimitar um recorte autoral ou uma temporalidade.

Para reconhecer contundentemente o aluno como sujeito, fonte e objeto da formação histórica, os docentes historiadores devem, portanto, definir outros territórios para sua práxis, como os da informação, do conhecimento e da comunicação, além das áreas das ciências humanas, exatas, da natureza e das linguagens, campos circunscritos à própria disciplina escolar e a saberes autoexplicativos.

0 PIBID História UFC promoveu rodas de conversas em sala de aula e falamos em momentos "curricularmente" oportunos (nas aulas cuja abordagem se deu sobre os temas Primeira e Segunda Guerras Mundiais, escravidão no Brasil, por exemplo), sobre como e por qual razão jornalistas, bibliotecários, arquivistas, youtubers, cineastas e documentaristas, por exemplo, escrevem sobre história ou se inserem num contexto histórico, trazendo à tona as suas especificidades narrativísticas, aquelas que já sabemos que são mais ouvidas e que falam bem mais alto aos jovens discentes se compararmos com as matérias de história e certas aulas expositivas moldadas na teoria da transmissão do conhecimento de quem sabe mais para quem sabe menos, de quem tem mais poder para quem tem menos.

A sala de aula é, dessa maneira, o lugar de ser e do dever ser da história pública, o espaço ao qual todos devem ter acesso e direito, inclusive, à história partilhada entre os historiadores e os literatos, pessoas que sabem tão bem perpetuar o principal artifício do método histórico: o enredo.

Seja por meio de canais no Youtube, seja através de revistas eletrônicas de história, de filmes de cunho historiográfico, a história pública está presente e pode se tornar um aliado do professor - que se torna um historiador público - na hora de ensinar o conteúdo. 0 docente também assume um papel ético, acadêmico, social e profissional quando faz uso e corrobora com a identificação da vontade de história pelos fazedores e usuários da história pública.

\section{A HISTÓRIA DO ALHEIO E O LIURO DIDÁTICO DE HISTÓRIA}

Não podemos esquecer que, nesse contexto, o principal instrumento usado em sala de aula por professores e alunos, para aprender e ensinar a história, é o livro didático de história. 0 único livro que boa parte dos estudantes possui, mesmo sem gostar, sem lê-lo e sem reconhecê-lo como livro (uma possível categoria do gênero literário), mas "apenas" como livro didático. Essa contradição, reconhecida pelos próprios pibidianos quando estudantes da 
educação básica, aproximou ainda mais o PIBID História UFC das questões emergentes da história pública.

E daí nossa relação com o livro didático e com os alunos, em sala de aula, foi de considerar que não existe nem existirá "o livro didático ideal" (SCHMDT; BARCA; MARTINS, 2010), mas versões históricas escritas por autores em seu tempo e por sua forma sobre um fato ou outro.

Com outra perspectiva, difundiu-se nas décadas de 1970 e 1980 os livros paradidáticos. Alguns dos seus títulos e histórias pretendiam ora "descortinar" a história ou contar "tudo" sobre o outro lado da história, ora reforçavam a história da verdade "nua e crua", os bastidores curiosos da história, em vez de ressaltar as muitas explicações históricas, princípio da ciência histórica.

Apesar disso, eram vendidos e comprados com o intuito de reforçar o conteúdo exposto pelo professor e acabaram sendo utilizados também por pessoas fora do ambiente escolar: "Focados em objetos específicos, podiam trazer tanto textos convencionais sobre o tema em estudo quanto pequenos enredos de ficção ambientados historicamente." (FONSECA, 2016, p. 187).

Desnaturalizar a autoria e o texto do livro didático, confrontando com outros livros didáticos, foi uma atitude crucial para o início da aceitação, pelos pibidianos e alunos das escolas, desse material como instrumento de consulta, pesquisa, leitura, crítica e aprendizado. Enfim, como um possível ponto de partida para o debate com a história enunciada por outras expressões culturais, como o filme, o documentário, a música e o teatro. Um exemplo pode ser encontrado no documentário lançado em 2012, 0 dia que durou 21 anos (0 DIA..., 2012), que aborda o conteúdo da Ditadura Militar no Brasil 1964-1985, unidade curricular dos livros didáticos contemporâneos de História do Brasil.

A história pública enquanto conceito produzido por causa da história alheia (de outrem, do público, de todos) estabelece suas intercessões com o mundo das representações filmicas, musicais e fotográficas, tendo como inspiração a história dos livros e dos livros didáticos, erguendo uma ponte entre a história contada no romance, no livro didático e a história contada no filme. Nesse caminho não há atritos da ficção com a realidade, somente o uso da força da imaginação histórica tentando domar, sem tanto sucesso (ainda bem), a representação utópica dos sujeitos que produzem livros e filmes.

Enquanto coordenadora de um dos programas mais consistentes na/da universidade, que interliga ensino de história e a formação docente no âmbito acadêmico e escolar, tive oportunidades de vivenciar experiências e identificar saberes históricos e pedagógicos associados à História Pública, ao dar aulas tendo como fonte e objeto o texto 
do livro didático de história e como paradigma a visão alteritária no processo de formação do pensamento histórico.

\section{5 “RESPEITÁUEL PÚBLICO”, OBRIGADA!}

A partir daqui nos despedimos (falo por mim e pelos demais integrantes do subprojeto PIBID História UFC dos anos de 2015, 2016, 2017 e início de 2018) deste artigo agradecendo ao público da escola e do PIBID UFC.

Nós aprendemos que é possível despertar o interesse dos jovens pela história utilizando os mecanismos de informação da História Pública, explicando aos alunos a importância da preservação e da consolidação da prática historiadora na vida de cada um e o direito ao acesso aos documentos públicos na/para a formação da consciência histórica. 0 acesso (como público e produtor) aos diversos meios de comunicação traz perspectivas pertinentes para debatermos sobre qual história os jovens estão se interessando, utilizando como instrumento de pesquisa o padrão de disseminação de conteúdo, as visualizações e likes de vídeos e sites e a dúvida e a curiosidade como elementos motivadores.

0s "males" que os conteúdos de certos sites podem causar aos jovens estudantes foram e são encarados e estudados considerando a ausência de debates sobre e do conhecimento dos arquivos e das fontes históricas, pois as fontes são ignoradas no ambiente virtual e não são cobradas pelos internautas. Esse juízo nos fez pensar em outra discussão recente, as fake news. Notícias falsas espalhadas em redes sociais como Facebook, Instagram e Twitter que não representam a realidade, mas que são compartilhadas na internet como se fossem verídicas. 0 objetivo de uma fake new é criar uma polêmica em torno de certas situações, eventos ou pessoas, contribuindo para a efetivação de outro dado informativo ou para a desinformação. Mas é também o reflexo da busca pela informação acelerada, da ausência de práticas de leituras e usos de fontes por parte de jovens, adultos e crianças.

Dessa forma, o nosso papel como PIBID foi compartilhar, com o apoio da teoria da didática da história na formação docente, a reflexão em torno da história pública em sala de aula a fim de questionar as formas públicas de apresentação da história em constante diálogo com o que é dito no meio social. É inegável a importância da história pública não só para o ensino de história, mas para a divulgação de forma responsável da história em/para diferentes públicos, inclusive no espaço acadêmico.

A história, assim como a ciência da natureza, serve para roteiro de diversos filmes, séries, novelas, histórias em quadrinhos e jogos. Hoje não é muito difícil ouvir, quando 
sabemos como e porque ouvir, os jovens conversando sobre Segunda Guerra Mundial, Revolução Russa e Ditadura Militar. Sobre isso o historiador Malerba (2014, p. 29) afirma:

0 entusiasmo pela história viva contagia as nações. No Brasil, onde os folhetins televisivos têm grande audiência, incontáveis minisséries de sucesso tiveram como enredo questões de fundo histórico. Seguindo a moda estrangeira, inúmeras revistas de história com fim de divulgação científica circulam hoje no país. Em suas mais diversas formas de apresentação popular, também aqui o passado nos cerca. Editores, publicitários e homens de mídia em geral descobriram que o passado pode representar bons negócios.

Os jovens têm recebido muitas informações históricas por meio do mercado da cultura pop, que tem se preocupado com o enriquecimento comercial de seus enredos e produtos (livros, roupas e acessórios, $\mathrm{HQ}$ s e jogos digitais), tendo a história antiga e medieval como meros conectivos para o que nos é tão caro, a cultura histórica e o passado.

Os docentes, por sua vez, perceberam que os estudantes se interessam bastante por videoaulas, e alguns professores costumam indicar canais ou eles mesmos acabam entrando "nessa onda" (fato que acompanhamos nas escolas onde o PIBID História atuava) e tornando-se youtubers. Contudo, a preocupação e o compromisso em conquistar a atenção dos alunos na sala de aula usando, no caso dos professores historiadores, a metodologia da investigação histórica ao analisar filmes, documentários e fontes históricas, ao refletir sobre os objetos e as pessoas de museus e arquivos, é o que há de mais sensível (por apelar para as sensibilidades dos sentidos do corpo juvenil) e empírico.

Não é só na sala de aula que o estudante forma e fortalece sua consciência histórica, e nós e os professores da educação básica sabemos disso: "A formação do estudante está relacionada às relações entre saber e agir na orientação do indivíduo, voltada especialmente a dimensão da vida prática do sujeito." (MOREIRA, 2017, p. 85). 0 aluno, ser histórico, é capaz de interpretar o mundo e a si mesmo, e sua noção de mundo é composta pelo que acontece também na sala de aula.

A relação entre história pública e a consciência histórica do sujeito, levando em conta sua individualidade e o seu cotidiano, foi mote para o intercâmbio ocorrido em junho de 2018, entre nós, pibidianos, o Grupo de Estudo e Pesquisa em Ensino de História (GEPEH) da UFC e a Escola Municipal de Ensino Fundamental José Mario Barbosa, localizada em uma área indígena Pitaguary no Município de Maracanaú, CE.

Os estudantes do $6^{\circ}$ e $7^{\circ}$ anos do Ensino Fundamental II dessa escola realizam um projeto de estudo e pesquisa histórica chamado Detetives da História, iniciado em 2015 e idealizado pela professora mestre Adriana Oliveira. 0 projeto de pesquisa exploratória objetiva ressignificar as tramas da memória e da identidade indígena dessa comunidade, uma vez 
que muitos de seus habitantes, alunos da escola, não se reconhecem como povo, de etnia indígena. 0s "detetives" elaboram e evidenciam, desse modo, o conhecimento da história desse lugar, tornando-a pública para a comunidade escolar e para seus familiares e vizinhos.

Esse exemplo também é bom para falar acerca da relação entre a história pública e a academia - representada aqui pelo PIBID História e GEPEH/UFC - e do crescente interesse que os historiadores acadêmicos estão tendo por esse campo, identificando-o como uma forma "positiva" de se fazer e estudar História.

Enfim, prezados professores e alunos de história das escolas Cesar Cals, Liceu de Messejana e Liceu do Ceará, "respeitável público", o PIBID História UFC agradece a acolhida, a participação e a audiência de todos durante a temporada de exibições e atuações das nossas mais variadas sequências didáticas que, em síntese, apregoavam sobre os usos da história pública na prática docente e a literacia histórica (BARCA, 2006, p. 93-112) como razão para ler e escutar o mundo historicamente.

\section{REFERÊNCIAS}

ALBIERI, S. História pública e consciência histórica. In: ALMEIDA, J. R.; ROVAl, M. G. 0. (org.). Introdução à história pública. São Paulo: Letra e Voz, 2011. p. 19-28.

ALMEIDA, J. R.; ROVAl, M. G. 0. Apresentação. In: ALMEIDA, J. R.; ROVAl, M. G. 0. (org.). Introdução à história pública. São Paulo: Letra e Voz, 2011. p. 7-15.

ARAÚJO, V. L. A aula como desafio à experiência da história. In: GONÇALVES, M. A. et al. Qual o valor da história hoje? Rio de Janeiro: Editora FGV, 2012. p. 66-77.

BARCA, I. Literacia história e consciência histórica. Revista Educar, p. 93-112, 2006. Edição Especial.

CERRI, L. F. Didática da história: uma leitura teórica sobre a história na prática. Revista de História Regional, v. 15, n. 8, p. 264-78, 2010.

CHARTIER, R. Do palco à página: publicar teatro e ler romances na época moderna: século XVI-XVIII. Rio de Janeiro: Casa da Palavra, 2002.

ENCONTRO ESTADUAL DE HISTÓRIA DO CEARÁ, 16., 2018, Fortaleza. Anais [...] Fortaleza: Universidade Federal do Ceará, 2018. Disponível em: https://eventos.uece.br/siseventos/processaEvento/evento/ exibeDetalhes. .jsf;jsessionid=7BA154E302F43E57DD1AE8270D2D70EA.eventoss2?.id=398\&area=indexEvento \&contexto=eehc2018. Acesso em: 29 ago. 2019.

FERREIRA, R. A. Qual a relação entre a história pública e ensino de história? In: MAUAD, A. M.; SANTHIAG0, R.; BORGES, V. T. (org.). Que história pública queremos? São Paulo: Letra e Voz, 2018. p. 29-38. 
FONSECA, T. N. L. Ensino de história, mídia e história pública. In: MAUAD, A. M.; ALMEIDA, J. R.; SANTHIAGO, R. (org.). História pública no Brasil: sentidos e itinerários. São Paulo: Letra e Voz, 2016. p. 185-194.

FREIRE, P. Ação cultural para a liberdade e outros escritos. Rio de janeiro: Paz e Terra, 1975.

MALERBA, J. Acadêmicos na berlinda ou como cada um escreve a História?: uma reflexão sobre o embate entre historiadores acadêmicos e não acadêmicos no Brasil à luz dos debates sobre Public History. História da Historiografia: revista eletrônica quadrimestral, n. 15, p. 27-50, ago. 2014.

MOREIRA, I. L. Sobre história pública e ensino de história: algumas considerações. EBR - Educação Básica Revista, v. 3, n. 2, p. 81-96, 2017.

0 DIA que durou 21 anos I Documentário Completo. [S. L.: s. n.], 2012.1 vídeo (79 min). Publicado pelo canal Filosofando Ciências humanas em debate. Disponivel em: https://www.youtube.com/ watch?v=4ajnWz4dIP4. Acesso em: 28 jul. 2020.

OLIVEIRA, T. A. D. (org.). Isabel Barca: pensamento histórico e consciência histórica. Teoria e Prática. Curitiba: W. A. Editores, 2018. p. 77-86.

PREFEITURA DE FORTALEZA. Academia Enem. Fortaleza: Prefeitura de Fortaleza, [2020]. Disponível em: https://juventude.fortaleza.ce.gov.br/academia-enem Acesso em: 15 ago. 2019.

PREFEITURA DE FORTALEZA. Prefeitura de Fortaleza abre inscrições para o Academia Enem 2017. Fortaleza: Prefeitura de Fortaleza, 23 mar. 2017. Disponível em: https://www.fortaleza.ce.gov.br/noticias/ prefeitura-de-fortaleza-abre-inscricoes-para-o-academia-enem-2017. Acesso em: 15 ago. 2019

SCHMIDT, M. A.; BARCA, l.; MARTINS, E. (org.). Jorn Rusen e o ensino de história. Curitiba: Ed. UFPR, 2011.

VALE, R. W. S. do. História, pesquisa e difusão cultural em arquivos: experiências no Arquivo Nacional. In: SIMPÓSIO INTERNACIONAL DE HISTÓRIA PÚBLICA, 2., 2014. Niterói. Anais [...] Niterói: Universidade Federal Fluminense, set. 2014. Disponivel em: http://historiapublica.com.br/simposio2014/?page_id=973. Acesso em: 29 ago. 2019.

WANDERLEY, S. Didática da história escolar: um debate sobre o caráter público da história ensinada. In: ALMEIDA, J. R.; MENESES, S. (org.). História pública em debate: patrimônio, educação e mediações do passado. São Paulo: Letra e Voz, 2018. p. 106-107.

Endereço para correspondência: Avenida da Universidade, 2762, Centro, Fortaleza, Ceará, Brasil; anacarlasabinofernandes2@gmail.com

Roteiro, Joaçaba, U. 45, p. 1-16, jan./dez. 2020 | e23056 |E-ISSN 2177-6059 